$\mathbb{T}$ periodica polytechnica

Transportation Engineering $41 / 2$ (2013) 95,98

doi: $10.3311 /$ PPtr.7108

http://periodicapolytechnica.org/tr

Creative Commons Attribution (1)

RESEARCH ARTICLE

\section{Relation between the Wetting Property and Electrical Conduction of Silver-Gold (Ag-Au) Alloys}

József Hlinka / Zoltán Weltsch

Received 2013-09-04

\begin{abstract}
The wettability of graphite by the silver-gold (Ag-Au) liquid alloy was measured using the sessile drop method at a temperature interval of $1273-1473 \mathrm{~K}$. The measured alloys are in the solid solution range. The system is found poorly wetting with the contact angle at an interval of $112 \ldots 136$ degrees. Typical alloying effects are found, as the Ag host metal is gradually replaced by Au alloying element. The results of the contact angle measurements were compared to the change of electrical resistance. The wetting angle measurement is complicated because several environmental variables affect the results. The wetting experiments were performed in a wetting angle measuring system which has changeable atmosphere, so the measurements can be performed in inert atmosphere and has a resistance-heated tube furnace which can ensure the wetting angle measuring temperature up to $1473 \mathrm{~K}$.
\end{abstract}

\section{Keywords}

wetting $\cdot$ contact angle $\cdot$ graphite $\cdot$ Ag-Au liquid alloy

\section{Acknowledgement}

This work has been supported by the Hungarian Scientific Research Fund (OTKA) through grant No. K-73690.

\section{József Hlinka}

Department of Automobiles and Vehicle Manufacturing, Budapest University of Technology and Economics, Stoczek J. u. 4., H-1111 Budapest, Hungary e-mail: jozsefhlinka@gmail.com

\section{Zoltán Weltsch}

Department of Automobiles and Vehicle Manufacturing, Budapest University of Technology and Economics, Stoczek J. u. 4., H-1111 Budapest, Hungary e-mail: weltsch@kgtt.bme.hu

\section{Introduction}

The significance of Ag-based alloys is important in brazing and welding processes (Andrews, [2]). The wetting phenomena between the filling alloy melt (brazing alloy) and the base material have a central role in obtaining sufficient quality, which serve the formation of steady joint between the parts. Alloying elements are also often used for this purpose in order to lower the melting point and also for increasing the wettability between the parts to be fixed. Nowadays the solders contain little amount of gold, because a few percent gold can increase the quality of the joint.

In earlier papers, where the theme of the investigation was the wetting angles of alloys with $\mathrm{Ag}$ host and $\mathrm{Cd}$, In, Sn, and Sb solvent metals, a systematic change determined in the solid solution range (Weltsch et al., [10]). The electrical resistance shows similar changes with the wetting angles of the alloys in the solid solution range.

The Ag-Au system creates solid solution on the whole concentration range as shown in Fig. 1 .

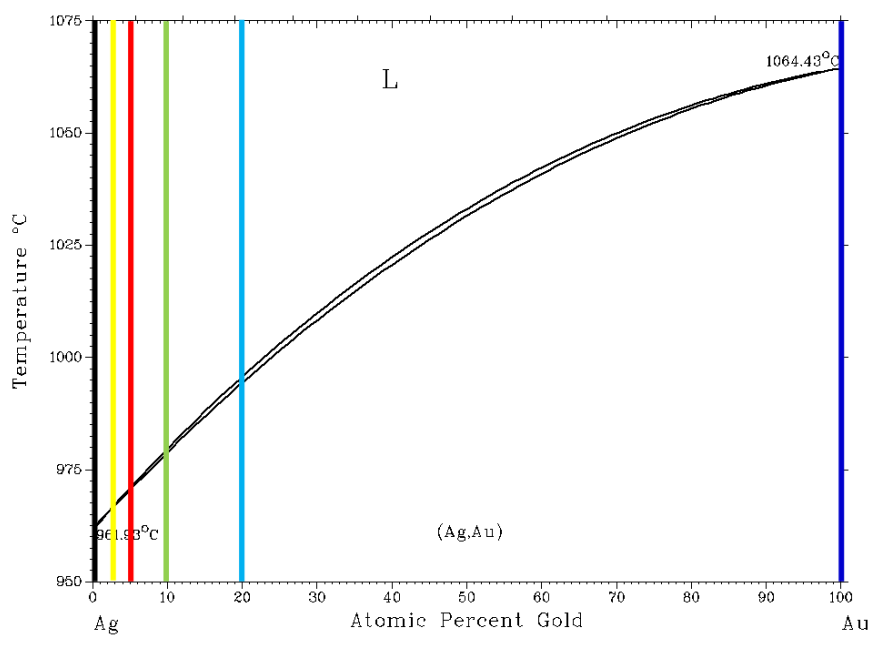

Fig. 1. Ag-Au binary phase diagram (Okamoto et al., [7])

The melting point of the silver and gold are in the measuring range of the resistance-heated tube furnace and the materials susceptibility to oxidation are low. In the Mendeleev periodic table the silver and gold are in the same column, so the 
e/a (electron/atom) ratio is the same. The atomic diameter of silver and gold are almost the same $\sim 2.88 \AA$ and $\sim 2.92 \AA$. Both elements have the same fcc crystal structure and there is no big difference between the electronegativities. Therefore the material pair meets the Hume-Rothery rules. The connection between the electrical resistance and the wetting properties can be verifiable in this system.

\section{Experiments}

The investigated alloys were prepared from high purity (4N) $\mathrm{Ag}$ and $\mathrm{Au}$, using induction melting in cold quartz crucible under inert (Ar) atmosphere. The graphite substrate was made from high purity, porosity free base material. The substrates were mechanically polished to $\mathrm{Ra}=0.23 \pm 0.005 \mu \mathrm{m}, \mathrm{r}=1.009 \pm$ $0.0005 \mathrm{Ra}$, the arithmetical mean line to a roughness profile; $r$, defined as the ratio of the true area of the solid surface to the apparent area). Surface roughness was determined using a 3D laser profilometer (Rodenstock RM600 surface topography measurement system) (Hlinka et al., [3]).

The surface roughness of the substrates has a profound and technologically important influence on the behaviour of wetting fluids. In one of the first studies the effects of surface roughness on the equilibrium contact angle $\left(\Theta_{0}\right.$ between wetting liquid and solid substrate) was reported by Wenzel (Wenzel [12]). He claimed that surfaces that wet $\left(\Theta_{0}<90^{\circ}\right)$ in smooth state will wet even better in rough state. Conversely, argued that if the smooth surface does not wet well, the rough surface wets even worse. This behaviour is expressed in the relationship

$$
\cos \Theta_{r}=r \cdot \cos \Theta_{0}
$$

where $\Theta_{r}$ is the contact angle on a surface with a roughness ratio $r$, given by the ratio of actual wetted surface area to geometric or projected area. According to (1), the rise of the roughness of a surface decreases the contact angle if $\Theta_{0}<90^{\circ}$, whereas it increases the contact angle if $\Theta_{0}>90^{\circ}$.

During the investigation the quality of the substrates surface were nearly constant. The deviations of the roughness parameters were low. Fig. 2 shows a 3D profile of the graphite substrate.

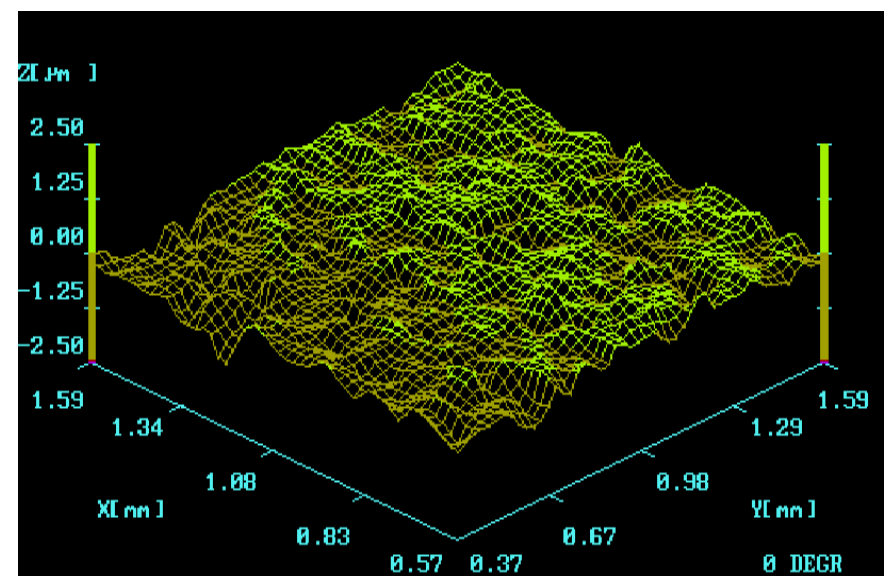

Fig. 2. Graphite substrate surface roughness
The wetting angle measurement is complicated because several environmental variables affect the results. Wetting experiments were performed in a wetting angle measuring system which can measure the wettability using sessile drop method (Fig. 3] (Hlinka et al., [3]), taking the methodological issues summarized by Sobczak (Sobczak et al., [8]) into account. The oxygen has bad impact on the accuracy of the wettability tests (Hlinka et al., [3]), that is the reason why the chamber has changeable atmosphere. Inert (Ar) atmosphere was used for the experiments in this paper. A resistance-heated tube furnace was used in order to ensure the high measuring temperature range.

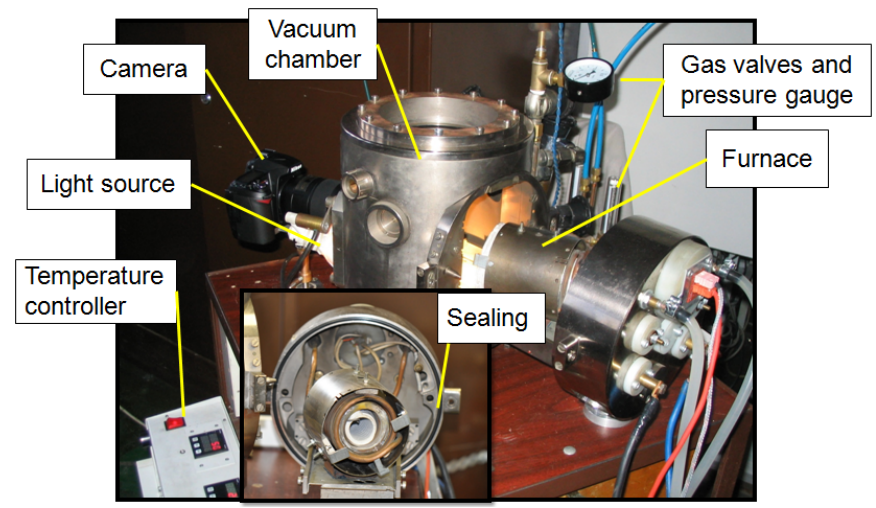

Fig. 3. Wetting angle measuring system

The graphite substrate and the alloy were positioned into the furnace at ambient conditions. The pressure was then reduced and the vacuum was replaced by a $10^{5} \mathrm{~Pa} 99.999 \%$ Ar gas. This procedure was repeated 3 times. Following this, the temperature was raised to $1000^{\circ} \mathrm{C}$ at a rate of about $4^{\circ} \mathrm{C} / \mathrm{s}$. Since only a small portion of the gas chamber is heated, the pressure around the droplet remains at about $10^{5} \mathrm{~Pa}$ during the measurements. Measurements were made at 1000, 1050, 1100, 1150 and $1200^{\circ} \mathrm{C}$.

The time dependence of the contact angle was reported in earlier paper by Weltsch. The contact angle does not depend on the holding time after 1 minute is passed from thermal equilibrium (Weltsch et al., [11]). Based on this, measurements after 2 minutes of holding time were used in this paper.

Matlab is widely used for system modeling, simulation and data evaluation (Németh et al., [5], Németh et al., [6]).

Contact angle values of the drop were measured directly from its images, processed by self-made automatic evaluation software in the Matlab environment. Although the uncertainty of this software was below $1^{\circ}$, the total uncertainty of the measured values was $\pm 3^{\circ}$.

After the last measurement at $1200^{\circ} \mathrm{C}$, the furnace was switched off and was left to cool to ambient temperature. This took about 40 minutes. After that, the furnace was dismounted and the sample was removed. The alloy sample was weighed before and after each experiment. The average weight loss was below $0.5 \%$ for pure $\mathrm{Ag}, \mathrm{Au}$ and for all $\mathrm{Ag}$-Au alloys. So the weight loss of the examined sample was not effect on the wetting test. 
The Ag-Au alloy compositions create homogeneous solid solutions on the whole concentration range. The measured alloy compositions were listed in Tab. 1

Tab. 1. Examined alloy compositions and their liquidus temperature

\begin{tabular}{lc}
\hline Alloy composition & Liquidus temperature of the alloy [ $\left.{ }^{\circ} \mathbf{C}\right]$ \\
\hline $\mathrm{Ag}$ & 961.93 \\
$\mathrm{Ag}_{97} \mathrm{Au}_{3}$ & 984.69 \\
$\mathrm{Ag}_{95} \mathrm{Au}_{5}$ & 991.22 \\
$\mathrm{Ag}_{90} \mathrm{Au}_{10}$ & 1009.18 \\
$\mathrm{Ag}_{80} \mathrm{Au}_{20}$ & 1040.82 \\
$\mathrm{Au}$ & 1064.43 \\
\hline
\end{tabular}

\section{Results}

In the whole concentration range the melts solidify in the form of single phase solid solutions with fcc crystal structure.

The wetting angles are illustrated as a function of the experimentally measured temperature. Fig. 4 shows that the wetting angles are rising while the temperature was increased. The shapes of the curves are still similar in every case. It is also remarkable, that the slope of each curve (except for the $\mathrm{Ag}_{97} \mathrm{Au}_{3}$ ) lower compared to the pure Ag. Remarkable the difference between the pure metals $\Theta(T)$, which may imply that Au solve less oxygen than Ag.

The slope of $\Theta(T)$ for the pure $\mathrm{Ag}$ is positive on graphite. This indicates the decreasing wetting ability of graphite versus the temperature, i.e. the $\mathrm{Ag} / \mathrm{graphite}$ interphase formation is energetically unfavorable, as the temperature increases (the interfacial energy increases) (Allen, [1]). The influence of alloying element amount on $\Theta(T)$ is the similar to the previous results of wettability measurements of Ag based solid solutions (Weltsch et al. , [10]).

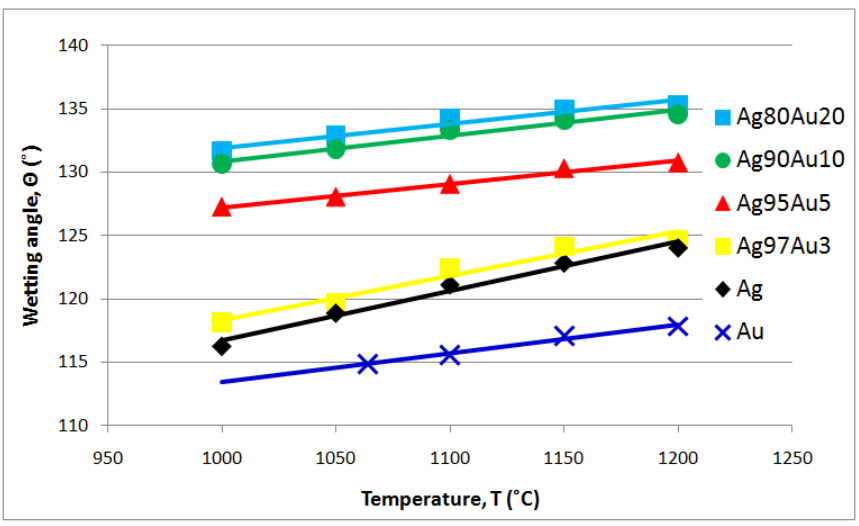

Fig. 4. The temperature dependence of the wetting angle of pure $\mathrm{Ag}, \mathrm{Au}$ and Ag alloyed with 3, 5, 10, 20 at.\% of Au on graphite substrate

As the phase-relation is very simple in this binary alloy system (single phase nature of liquids and the solid solutions), one can suppose that the alloying induced by the electron concentration has a detectable impact not only in the stabilization of liquid state (melting point suppression) but also in the surface energy of the liquid drop. The magnitude of the wetting angle depends only indirectly on the total surface energy, which is composed from the drop/gas and the drop/substrate interface components (Kaptay, [4]).

Fig 5 shows the electrical resistance changes of the AgAu alloy system. The changes follow through a typical tub curve. The pure materials have much better electrical conduction properties than the alloys, especially the medium alloyed ones. The $\mathrm{Ag}$ has the best electrical conductivity of all elements. Small amount of alloying Au content has a drastic effect on electrical conductivity of Ag. Correlation can be found between the wetting angle changes and the electrical conduction changes. When the amounts of alloying elements are increased the difference between the pure material and the alloy is bigger in both properties.

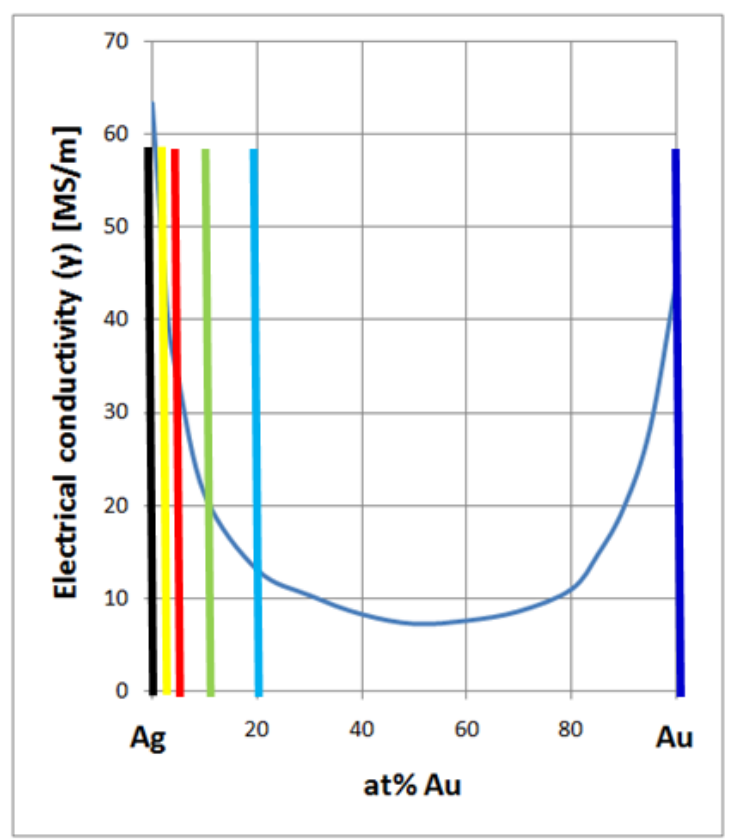

Fig. 5. Electrical conduction of Ag-Au alloys (Verô et al., [9])

The ratio of the electrical conduction and wetting angle changes are shown in Fig. 6 The ratio were calculated from the difference between the pure Ag and the alloy compositions and correlated to the biggest difference. The rate of change of the electrical conduction and wetting angle changes seems to be similar in the $\mathrm{Ag}_{95} \mathrm{Au}_{5}, \mathrm{Ag}_{90} \mathrm{Au}_{10}, \mathrm{Ag}_{80} \mathrm{Au}_{20}$ samples. The results of $\mathrm{Ag}_{97} \mathrm{Au}_{3}$ show bigger difference. The change of wetting angle is smaller than the change of electrical conduction. The alloying effect is less relevant for the wetting angle in case of $\mathrm{Ag}_{97} \mathrm{Au}_{3}$ alloy composition.

\section{Conclusion}

The temperature dependence of wetting angle is measured on graphite for Ag-Au melts. The slope of $\Theta(T)$ for the examined $\mathrm{Ag}-\mathrm{Au}$ compositions are positive on graphite. In this system the wetting angle changes of the solid solutions are followed the rules that determined in earlier papers (Weltsch et al., [10]). The increase of the alloying element in the alloy composition, increase the wetting angles (the wettability is getting worse). 


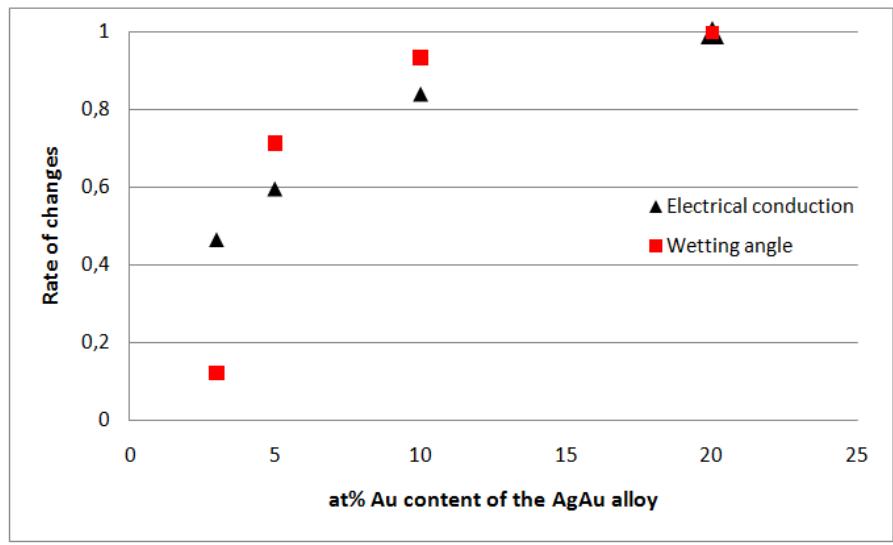

Fig. 6. Property changes of the investigated alloys

Connection determined between the changes of wetting angle - which was measured in molten state of the sample - and electrical conduction - which was measured in solid state of the sample. The shifts of wetting angles are the same in the electrical conduction.

The knowledge of the wettability changes in solid solutions and the correlation between wettability and electrical conduction can help to compose the suitable solder alloy composition for the purpose.

\section{References}

1 Allen BC, Surface Tension in Liquid Metals, Chemistry and Physics, (1972), 165-197.

2 Andrews DR, Soldering brazing welding and adhesives, Institution of Production Engineers; London, 1978.

3 Hlinka J, Weltsch Z, Berzy J, Szmejkál A, Impovements of Sessile Drop Method for the Wetting Angle Determination, Perner's Contact, 6 (Special Issue 2), (2011), 64-71.

4 Kaptay G, Classification and general derivation of interfacial forces, acting on phases, situated in the bulk, or at the interface of other phases, Journal of Materials Science, 40(9-10), (2005), 2125-2131, DOI 10.1007/s10853-0051902-2

5 Németh B, Gáspár P, Vehicle modeling for integrated control design, Periodica Polytechnica Transportation Engineering, 38(1), (2010), 45-51, DOI 10.3311/pp.tr.2010-1.08

6 Németh B, Gáspár P, Model-based LQ control design of integrated vehicle tracking systems, Periodica Polytechnica Transportation Engineering, 39(2), (2011), 77-81, DOI 10.3311/pp.tr.2011-2.05

7 Okamoto H, Massalski TB, Phase Diagrams of Binary Gold Alloys, ASM International; Metals Park, Ohio, 1987.

8 Sobczak N, Singh M, Asthana R, High-temperature wettability measurements in metal/ceramic systems - some methodological issues, Current Opinion in Solid State and Materials Science, 9(4-5), (2005), 241-253, DOI 10.1016/j.cossms.2006.07.007

9 Verö J, Káldor M, Fémtan, Nemzeti Tankönyvkiadó; Budapest, 1977.

10 Weltsch Z, Lovas A, Tichy G, Vandrus Z, Bulk Electron Concentration and the Surface Tension of Liquid Ag-Based Solutions, Perner's Contact, 6(Special Issue 2), (2011), 221-27.

11 Weltsch Z, Lovas A, Takács J, Cziráki Á, Toth A, Kaptay G, Measurement and modelling of the wettability of graphite by a silver-tin (Ag-Sn) liquid alloy, Applied Surface Science, 268(1 March 2013), (2013), 52-60, DOI $10.1016 /$ j.apsusc.2012.11.150

12 Wenzel RN, Resistance of solid surfaces to wetting by water, Industrial \& Engineering Chemistry Research, 28(8), (1936). 